\title{
Characteristics of flux-time profiles, temporal evolution, and spatial distribution of radiation-belt electron precipitation bursts in the upper ionosphere before great and giant earthquakes
}

\author{
Georgios C. Anagnostopoulos ${ }^{1}$, Efthymios Vassiliadis ${ }^{1}$, Sergey Pulinets ${ }^{2,3}$
}

\author{
${ }^{1}$ Space Research Laboratory, Democritus University of Thrace, Xanthi, Greece \\ ${ }^{2}$ Fiodorov Institute of Applied Geophysics, Moscow, Russia \\ ${ }^{3}$ Space Research Institute, Russian Academy of Sciences, Moscow, Russia
}

\author{
Article history \\ Received August 11, 2011; accepted January 22, 2012. \\ Subject classification: \\ Electromagnetic earthquake precursors, Ionospheric precursors of earthquakes, Radiation belt electron precipitation, Lithosphere-ionosphere \\ Coupling, Wave particle interaction.
}

\section{ABSTRACT}

The analysis of energetic electron observations made by the DEMETER satellite reveals that radiation belt electron precipitation (RBEP) bursts are observed in general several $(\sim 1-6$ days) before a large $(M>6.5)$ earthquake (EQ) in the presence of broad band $(\sim 1-20 \mathrm{kHz}) \mathrm{VLF}$ waves. The EBs show in general a relative peak-to-background flux increase usually $<100$, they have a time duration of $\sim 0.5-3 \mathrm{~min}$, and their energy spectrum reach up to energies $<\sim 500 \mathrm{keV}$. The RBEP activity is observed as one, two or three EBs throughout a semi-orbit, depended on the magnetic field structure above the EQ epicenter. A statistical analysis has been made for earthquakes in Japan, which reveals a standard temporal variation of the number of EBs, which begins with an incremental rate several days before major earthquakes, and after a maximum, decreases so that the electron precipitation ceases above the epicenter. Some earthquake induced EBs were observed not only in the nightside ionosphere, but also in the dayside ionosphere.

\section{Introduction}

1.1 Electromagnetic methods of earthquake precursory signals research

Over the last few decades, significant efforts have been made to detect and interpret electromagnetic phenomena that are related to seismic activity. Due to these efforts, characteristic physical changes have been confirmed as precursor signals of earthquake preparation. To this end, several methodologies have been developed that use groundbased instrumentation to detect electromagnetic variations that occur in the lithosphere [Kopytsenko et al. 1990, Hayakawa et al. 1996a, b, Varotsos et al. 1998, Hattori 2004, Eftaxias et al. 2007].

Other studies have shown that before strong earthquakes, there are characteristic electromagnetic interactions in the ionosphere that are observed as plasma variations or electromagnetic (ultra-low frequency - ULF, very-low frequency - VLF) emissions, detected by either ground-based [Hayakawa et al. 1996a, b, Pulinets and Boyarchuk 2004; Hattori 2004] or space-based [Boskova et al. 1994, Pulinets and Legen'ka 2003, Parrot 2006, Ouzounov et al. 2011, Pulinets and Ouzounov 2011] instrumentation. For instance, Rozhnoi et al. [2007] recently studied earthquakes in Japan by investigating the ionosphere using VLF broadcasting between a transmitter in Japan and a receiver in Russia.

In addition to the electromagnetic phenomena that can take place in the lithosphere and the ionosphere, electromagnetic processes related to seismic activity affect the trapped population of the radiation (Van Allen) belts, and several studies have reported satellite measurements that have suggested that there are radiation belt energetic particle flux variations accompanied by VLF electric field activity before earthquakes [Ginzburg et al. 1994, Galper et al. 1995, Pulinets and Boyarchuk 2004, and references therein; Sgrigna et al. 2005, Aleksandrin et al. 2003, Fidani et al. 2010, Anagnostopoulos and Rigas 2009, Anagnostopoulos et al., 2010, Sidiropoulos et al. 2011].

1.2 Physical and anthropogenic sources that trigger radiationbelt electron precipitation

The precipitation of energetic electrons from the Van Allen belts (radiation-belt electron precipitation; RBEP) in the upper ionosphere at middle and low latitudes has been a well-known phenomenon for many years [Paulikas 1975, Vampola 1983, Kuznetsov and Myagkova 2002]. The major sources of this process were considered to be the powerful military VLF transmitters [Vampola 1983, Abel and Thorne 1998, Green and Fung 2005] and natural processes, such as 
the earthquakes [Ginzburg et al. 1994, Pulinets and Boyarchuk 2004, and references therein] and lightening [Inan et al. 2007].

It has been hypothesized that cyclotron-resonant interactions of trapped electrons via scattering by lighteninggenerated whistler waves is a significant process in the loss of electrons from the radiation belts. The most recent concepts concerning cyclotron resonance interactions of VLF emissions with the particles of radiation belts can be found in Trakhtengerts and Rycroft [2008].

On the other hand, many studies have indicated the powerful military VLF transmitters as the main physical process that causes electron precipitation at middle latitudes. For instance, based on theoretical calculations, Abel and Thorn [1998] arrived at the hypothesis that manmade transmissions dominate the losses in the inner radiation belt, and Vampola [1983] claimed that, «if satellites replace the VLF transmitters for both communication and navigation, we may have a chance to observe the slot (between the inner-outer belt) refill and remain filled». Vampola [1983] also suggested that, "We might have to continue to radiate VLF waves at high power levels in order to protect low altitude satellites». We would indicate that this belief is acceptable to a significant part of the scientific community, although we are not aware of any statistical scientific study up to the year 2010 that has supported this hypothesis. A possible reason for this belief is the traditional interface between ionospheric/plasma physics and radio communications, whereas earthquake-induced radiationbelt electron precipitation as another candidate source of RBEP is a recently developed research field. To estimate the relative contributions of the two sources, as the great earthquakes and the ground-based transmitters, a recent study presented the first statistical analysis of RBEP burst characteristics [Sidiropoulos et al. 2011]. First, Sidiropoulos et al. [2011] identified two types of electron bursts (EBs) on the basis of the different forms of the related electric field spectrum: VLF transmitter-induced EBs are related to the presence of a narrow band emission that is centered at the transmitter radiating frequency emission, whereas the earthquake-related EBs are related to the presence of broadband emissions (from $2 \mathrm{kHz}$ to $>\sim 20 \mathrm{kHz}$ ). Secondly, Sidiropoulos et al. [2011] demonstrated that although the North West Cape (NWC) transmitter (in western Australia) is the most powerful military transmitter $(1 \mathrm{MW})$, in that it produces the strongest electron precipitation effects compared with all of the other transmitters over the globe, NWC-induced EBs are observed during only $\sim 2.1 \%$ of the Detection of Electromagnetic Emissions Transmitted from Earthquake Regions (DEMETER) satellite passes above the transmitter-influenced region $\left(25^{\circ}-30^{\circ} \mathrm{S}, 114^{\circ}-167^{\circ} \mathrm{E}\right)$, with the NWC-associated EBs (including the conjugate EBs) as low as $<\sim 1.5 \%$ of the whole number of EBs. Sidiropoulos et al. (2001) also provided clear evidence opposing the hypothesis that man-made transmissions dominate the losses in the inner radiation belt. They showed that more EBs were observed when the NWC transmitter was off (449) than during a similar $\sim 6$-month interval when the transmitter was on (374); on the contrary, in agreement with the assumption that seismic activity provides the most intense contribution to RBEP events, a higher number of great earthquakes were found in the first period (14 earthquakes) than in the second period (5 earthquakes). Based on previous statistical analyses, Sidiropoulos et al. (2011) suggested that seismic activity dominates the electromagnetic interactions that produce the $\sim 70 \mathrm{keV}$ to $500 \mathrm{keV}$ RBEP events that last for $\sim 2$ min to $3 \mathrm{~min}$ at middle latitudes; therefore seismic activity dominates the losses in the inner radiation belt.

In this report, we attempt to provide an advance in the study of RBEP events observed before great earthquakes (M 26.5). To this end, we classify the flux-time profiles of RBEP events in some distinct forms at characteristic seismogenic regions all over the globe by investigating the DEMETER satellite observations before recent large earthquakes (Honshu, Japan, 2005; Sumatra, Indonesia, 2005; Andravida, Greece; south-easern Europe, 2008; Haiti, central America, 2010; and Chile, south-eastern America, 2010). In addition, we demonstrate the existence of a standard temporal variation in the number of RBEP events before the occurrence of great earthquakes $(M>6.7)$ in Japan, based on a statistical analysis. Furthermore, the detailed analysis of the combined temporalspatial distribution of the RBEP events for one of the Japan earthquakes (August 16, 2005) included in the statistical sample of a previous study reveals that at around the time of the maximum EB rate, the EB spatial distribution showed a broad dispersion in longitudes, and then the RBEP event coordinates were reduced around the region of the earthquake epicenter. A few hours before the earthquake occurrence, a silence in the RBEP in the upper ionosphere above the region of the epicenter was recorded.

\section{The DEMETER mission and instrumentation}

In this report, we present the results from an analysis of the EBs observed by the DEMETER satellite (http://demeter.cnrs-orleans.fr/) [Parrot 2006]. The DEMETER satellite was designed and built specifically for the research of earthquake precursory signals, and it was launched on June 29,2004 , into a sun-synchronous, almost polar (inclination, $98.3^{\circ}$ ), orbit, at $\sim 710 \mathrm{~km}$ in altitude, where it performed 16 orbits per day. Its orbit was lowered to $660 \mathrm{~km}$ in altitude in 2005, and it stopped operation in December 2010.

The primary scientific objective of DEMETER was the detection and characterization of ionospheric and radiationbelt disturbances related to seismic or human activities. 
Consequently, the scientific payload of the satellite was composed of several types of sensors that measure waves and particles, which included an instrument for the detection of particles (IDP), and an electric field instrument (Instrument Champ Electrique; ICE). Data from these two instruments were used in the present study and are presented in the next section.

The IDP electron spectrometer [Sauvaud et al. 2006] covers all energies from $0.07 \mathrm{MeV}$ to $2.5 \mathrm{MeV}$, across 256 energy bands. In the present study, the IDP electron intensities were averaged over three energy bands: $72 \mathrm{keV}$ to $526 \mathrm{keV}$ (Band 1), $526 \mathrm{keV}$ to $971 \mathrm{keV}$ (Band 2) and $971 \mathrm{keV}$ to $2350 \mathrm{keV}$ (Band 3). The ICE measurements were made over a wide frequency range of electromagnetic and/or electrostatic waves from direct current (DC) to $3.175 \mathrm{MHz}$, subdivided into four frequency channels DC/ULF, extremely low frequency (ELF), VLF and high frequency (HF). Here we use the measurements from the VLF channel in the frequency band of $0 \mathrm{kHz}$ to $20 \mathrm{kHz}$.

For the IDP, there were two modes of operation, the 'burst' and 'survey' modes. The burst mode had a time resolution of $1 \mathrm{~s}$ and it was applied automatically when the satellite was over-flying areas that had been identified as seismically active. When DEMETER moved away from these seismically active regions, it returned to the survey mode, with a time resolution of 4 s.It is well known that within the Van Allen belts electrons and ions follow spiral trajectories around the field lines of the Earth magnetic field, while protons and electrons drift perpendicular to the magnetic field in the opposite direction. At the same time, ions and electrons moving towards higher latitudes are reflected at sites of strong magnetic field and are trapped within the inner and the outer Van Allen belts. The EBs associated with an earthquake at low and middle geographic latitudes manifest radiation electron precipitation, and this process has been considered as one of the links in a long chain of electromagnetic processes in the lithosphere-atmosphereionosphere-plasmasphere-magnetosphere coupling [Pulinets and Boyarchuk 2004, Anagnostopoulos and Papandreou 2012].

\section{Observations}

3.1 Flux-time profiles of radiation-belt electron bursts

We examined anomalous energetic EBs detected by the IDP experiment, accompanied by the VLF electric field activity from the ICE instrument that was on board DEMETER, for the whole period of the satellite life from 2004 to 2010. A thorough investigation of IDP electron observations for a time interval of 30 days before and 10 days after a large number $(>30)$ of great earthquakes all over the globe reveals a variety of flux-time profiles of radiation belt EBs that can be categorized into certain well-defined forms.
We will classify the flux-time profiles of pre-seismic RBEP events into some distinct categories.

Figure 1 presents the observations of the DEMETER satellite during the upward semi-orbit numbered 5952_1, about half a day before the earthquake of August 16, 2005, in eastern Honshu, Japan. Figure 1 shows, from top to bottom, (a) the dynamic spectrogram of the electric field in the frequency range $0 \mathrm{kHz}$ to $20 \mathrm{kHz}$, (b) the intensity of the electrons from the IDP experiment in the energy bands $72 \mathrm{keV}$ to $526 \mathrm{keV}$ (Band 1), $526 \mathrm{keV}$ to $971 \mathrm{keV}$ (Band 2) and $971 \mathrm{keV}$ to $2350 \mathrm{keV}$ (Band 3), and (c) semi-orbit 5952_1 projected onto an Earth map. The universal and local time, as well as the longitude and the latitude of the position of DEMETER during the time period examined in Figure 1, are noted below panel (b). As we said in the previous section, the IDP instrument operated in two modes: the burst and survey modes. The burst mode was applied automatically when the satellite was over-flying areas that are shown in red on the map (Figure 1c); when DEMETER moved away from these seismically active regions, it returned to the survey mode.

During the DEMETER semi-orbit, enhanced electron fluxes are evident on the left as well as on the right edge of Figure $1 \mathrm{~b}$. Two pairs of large-intensity enhancements at the south and north latitudes correspond to the nearest edges of the Earth outer and inner radiation electron belts, in the south and north hemispheres, respectively. Large flux enhancements at high south $\left(\sim 43^{\circ}-54^{\circ} \mathrm{S}\right)$ and north $\left(\sim 61^{\circ}-71^{\circ} \mathrm{N}\right)$ latitudes are evident in all of the three electron bands, while the inner enhancements at middle south $\left(\sim 32^{\circ}-39^{\circ} \mathrm{S}\right)$ and north $\left(\sim 52^{\circ}\right.$ $57^{\circ} \mathrm{N}$ ) latitudes are evident only in band 1 and band 2 . The pairs of flux enhancements at south and north latitudes were very often observed by IDP during the DEMETER semi-orbits from south to north, depending on the longitude. The short sudden flux increases at $\sim 12: 48\left(\sim 29^{\circ} \mathrm{S}\right)$ UT and $\sim 13: 09$ UT $\left(\sim 47^{\circ} \mathrm{N}\right)$, which were superimposed on the low-energy (band 1) flux-time profile (Figure 1b, purple arrows) that was observed as long as the intensity of the inner large-flux enhancement decreased towards the equator (Figure 1b, near the middle of the plot), lasted for $\sim 1 \mathrm{~min}$ and $\sim 2 \mathrm{~min}$ (including the two peaks in the second case), and they are examples of the RBEP events observed earlier by DEMETER for several days before the strong earthquake in eastern Honshu. These two short-lived peaks fall into the set of EBs identified in the studies by Anagnostopoulos et al. [2010] and Sidiropoulos et al. [2011], as precursor signals of the earthquake that occurred at 02:46:31 UT, on August 16, 2005, near the east coast of Honshu, Japan.

The EB at 13:09 UT on August 15, 2005, was observed during an anodic (night-time) semi-orbit that passed westwards of the future Japan earthquake epicenter $\left(44.5^{\circ} \mathrm{N}\right.$, $125.6^{\circ} \mathrm{E}$ ). As the energetic electrons travel along the magnetic field lines, they can obviously produce a conjugate EB in the 


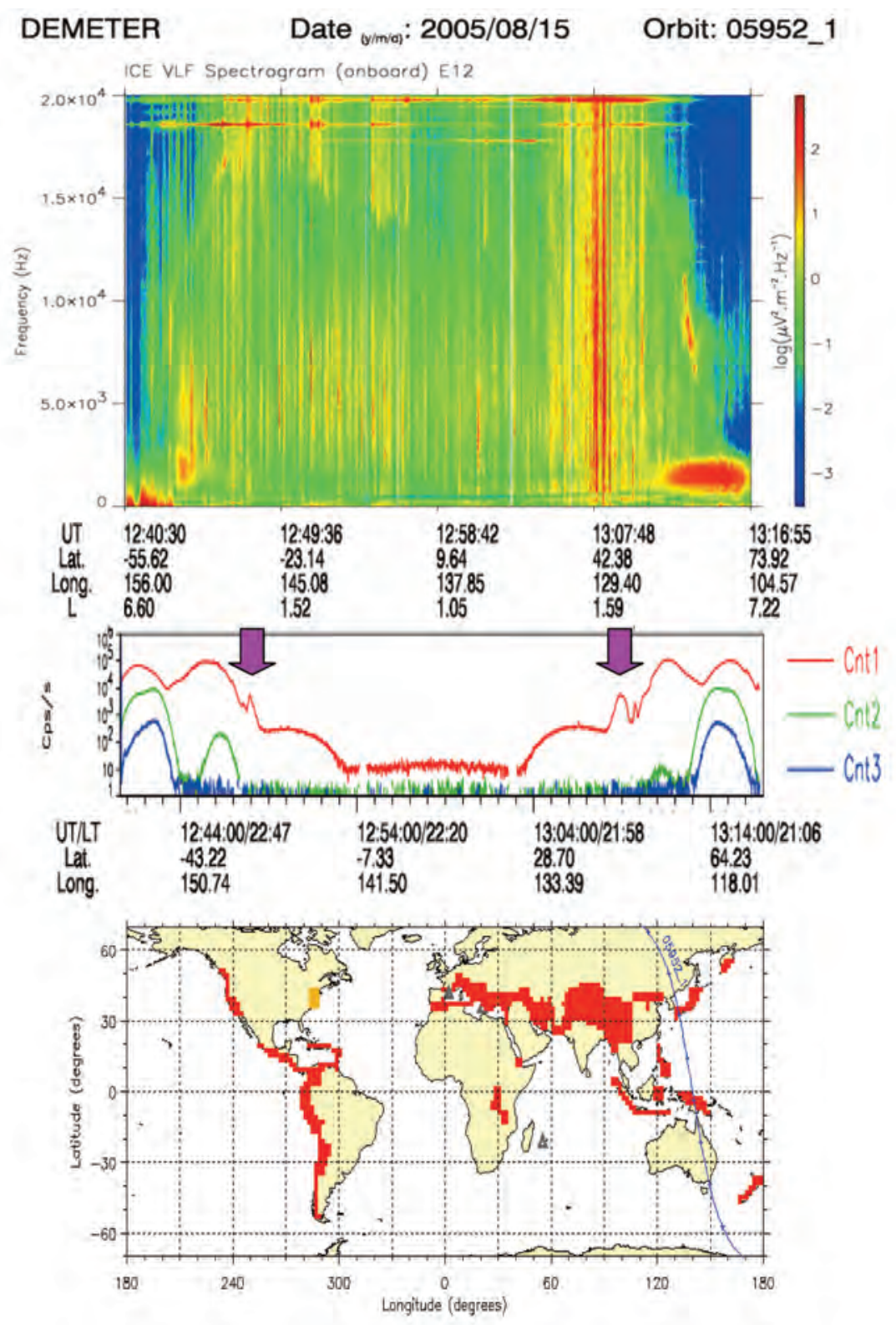

Figure 1. Observations from the DEMETER satellite during an upward semi-orbit, about half a day before the earthquake of August 16, 2005, in eastern Honsu, Japan. (a) Spectrogram of the electric field in the frequency range $0 \mathrm{kHz}$ to $20 \mathrm{kHz}$. (b) The intensity of the electrons from the IDP experiment in the energy regions of $72 \mathrm{keV}$ to $526 \mathrm{keV}, 526 \mathrm{keV}$ to $971 \mathrm{keV}, 971 \mathrm{keV}$ to $2350 \mathrm{keV}$. (c) The DEMETER orbit projected on an Earth map. An electron intensity peak at $\sim 12: 48\left(\sim 29^{\circ} \mathrm{S}\right)$ UT in (b) is well correlated with a strong broadband VLF signal observed near the earthquake epicenter.

southern hemisphere that is most probably the EB seen at $\sim 12: 48$ UT, and its presence was already noted above. The position of the conjugate $\mathrm{EB}\left(147^{\circ} \mathrm{E}, 29^{\circ} \mathrm{S}\right)$ appears above eastern Australia.

In the electric field spectrogram of Figure 1a, a strong VLF signal can be seen that was observed almost simultaneously with the EB near the earthquake epicenter. This signal is dispersive and extends in frequencies all over the scale of Figure 1a, ranging from $0 \mathrm{kHz}$ to $20 \mathrm{kHz}$. On the contrary, the EB observed above Australia is not related to a strong VLF emission. This differentiation in the strength of the electric field is self-consistent with the suggestion above: that the EB in the south should be the conjugate (not the original) RBEP event formed in the south hemisphere. We also note that a narrow-band signal in the spectrogram of Figure 1 is also present around the NWC transmitter radiating frequency of $19.8 \mathrm{kHz}$ over a large portion of the time examined in Figure 1 , while the near Japan EB is very well correlated with the time of the intense broadband VLF emission. We believe that the time coincidence of the occurrence of the EB with the intense broadband VLF emission confirms that in this case the earthquake in Japan had the main role in the production of the electron precipitation at $\sim 13: 09$ UT on August 15, 2005. Examination of the energy spectra of the anomalous strong EB observed near the earthquake epicenter at $\sim$ 13:09 shows a type with a hardening toward the equator. The spectrum of this EB extends up to $\sim 500 \mathrm{keV}$. The EB observed at the conjugate region is a little less intense and lasts for a shorter 
time, and its spectrum extends up to lower energies $(\sim 430$ $\mathrm{keV})$. In general, our investigations suggest that the EBs preceding earthquakes that occur at middle latitudes show similar spectra that usually extend up to $200 \mathrm{keV}$ to $500 \mathrm{keV}$.

Figures 2-5 are constructed in the same format as Figure 1 , and they indicate the characteristic RBEP events observed before some other famous strong earthquakes that occurred in various seismogenic regions around the globe. Figure 2 presents the DEMETER data obtained one day before the famous recent giant earthquake in Chile $(\mathrm{M}=8.8$; February $\left.27,2010,287.1^{\circ} \mathrm{E}, 36^{\circ} \mathrm{S}\right)$ near the epicenter longitudes. Zhang et al. [2010] reported that DEMETER detected an enhancement of counting rates of low-energy charged particles in the $90.7 \mathrm{keV}$ to $\sim 600 \mathrm{keV}$ region 13 days before the occurrence of the earthquake, during orbits within a range of $10^{\circ}$ and $0.1 \mathrm{Mc}-$-Ilwain parameter value $\mathrm{L}$ across the epicenter region (287.1E, $\mathrm{L}=1.32$ ). Zhang et al. [2010] inferred that the bursts examined were likely to be related to the Chile earthquake and can be taken as the precursor of this earthquake. Zhang et al. [2010] studied charged particle flux increases only during upward DEMETER semi-orbits, which correspond to night observations.

As indicated in the Introduction, a major (or the main) source of the electron precipitation observed at middle latitudes has been previously assumed to be ground-based transmitters. Ground-based transmitter-induced RBEP events are observed only for night-time semi-orbits, almost certainly due to the much lower ionospheric absorption of

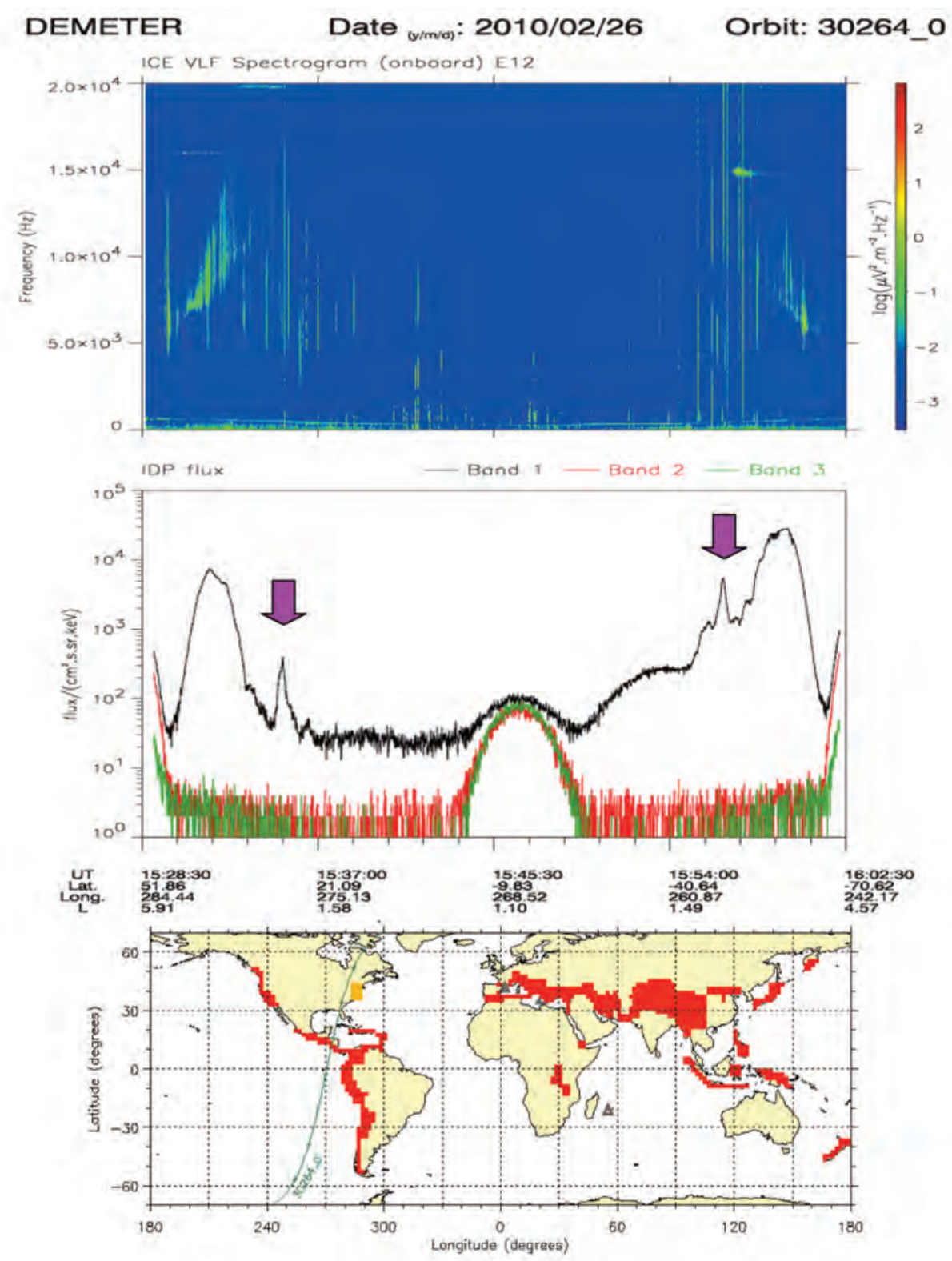

Figure 2. Observations from the DEMETER satellite during an upward semi-orbit, for the day before the giant earthquake of February 27, 2010, in Chile $\left(\mathrm{M}=8.8,287.1^{\circ} \mathrm{E}, 36^{\circ} \mathrm{S}\right)$. Details as for legend to Figure 1. Two EBs were observed in the dayside upper ionosphere, with one above the future epicenter and a conjugate one in the north hemisphere. 


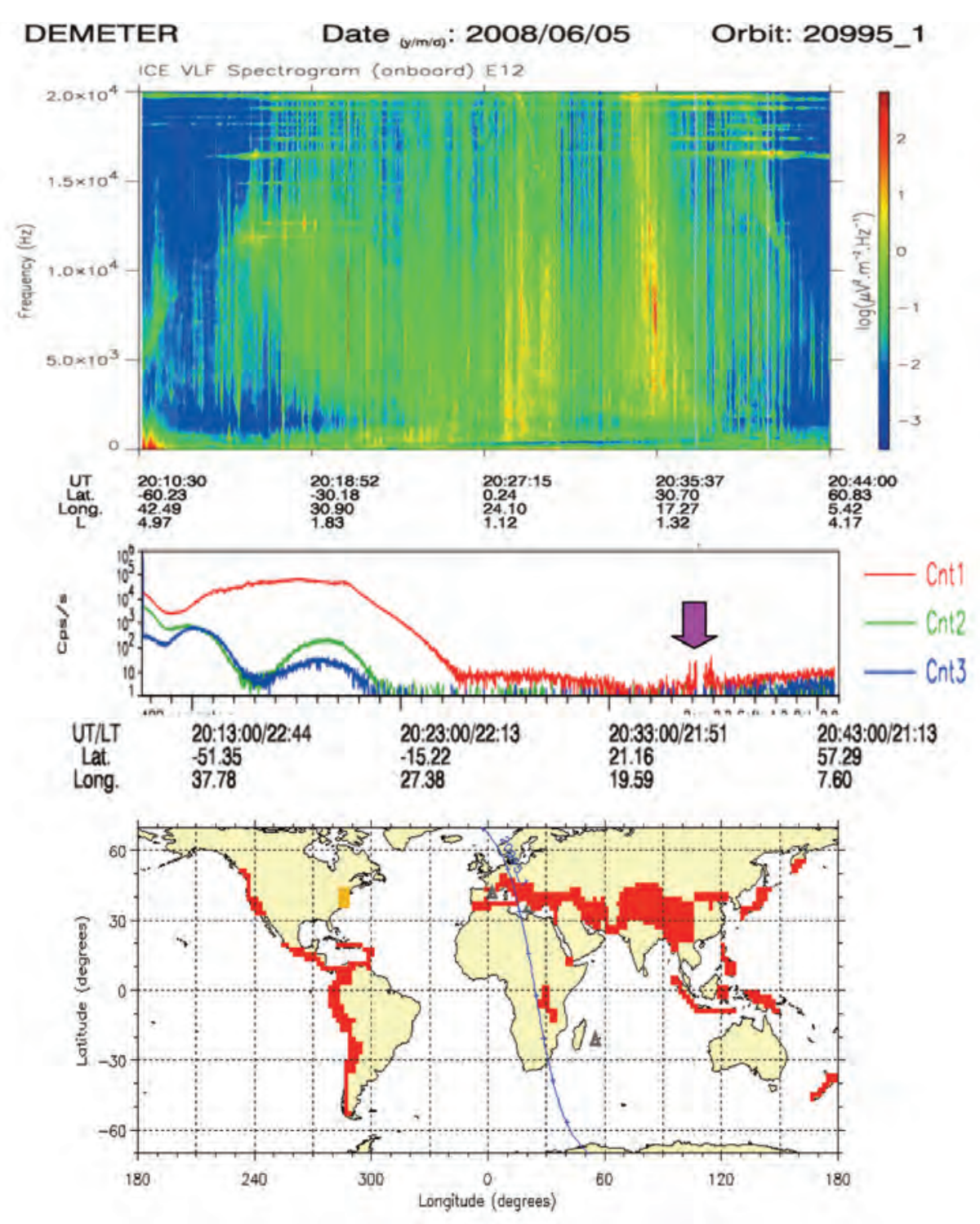

Figure 3. Observations from the DEMETER satellite on June 5, 2008, about three days before the occurrence of an earthquake in Andravida, Greece. The electron enhanced activity recorded at a geographic latitude $\left(37.93^{\circ} \mathrm{N}\right)$ similar to that of August 16,2005 , earthquake in Japan $\left(38.3^{\circ} \mathrm{N}\right)$, although instead of one peak superimposed on the (high) flux background in Japan, a sequence of electron peaks are evident here (b) under a very low background flux level. The EB is well related in time to the presence of a broadband $(\sim 2-19 \mathrm{kHz}) \mathrm{VLF}$ activity (a).

the emitting radiation through the night-time ionosphere. To further check the origin of the RBEP events observed near the Chile earthquake, we wanted to examine the presence of energetic electron activity at local day times, when the VLF radiation emitted from the ground cannot produce strong RBEP events [Sauvaud et al. 2008]. For this reason, Figure 2 shows data obtained during the downward (daytime) DEMETER semi-orbit 30264_0. The electric field spectrogram shows a distinct difference in comparison to the night-time spectrogram of Figure 1. Here, the electric field spectrum was quieter; only some low VLF electric field energy was present, and no characteristic ground-based emissions (horizontal signals at a certain radiating frequency) can be seen in Figure 1. However, a strong RBEP burst with a peak-to-background flux increase as large as $\mathrm{p} / \mathrm{b} \approx 20 \mathrm{can}$ be seen centered at $\sim 16: 01 \mathrm{UT}$, with a duration time of $\sim 1$ min and accompanied by some light broadband VLF activity (Figure 2a, normal lines) during the passage of the DEMETER satellite near the Chile earthquake epicenter region. In addition, a distinct peak of lower intensity at north latitudes is evident, which is most probably the conjugate earthquake-induced RBEP event.

We point out that such an electron burst with a peakto-background flux increase as large as $p / b \approx 20$, as detected by DEMETER before the giant earthquake in Chile in the daytime upper ionosphere, has not been reported in the scientific literature as being caused by ground-based emitted VLF radiation (not observed by the satellite), as far as we know. Therefore, we infer that the EB of February 26, 2010, almost certainly appeared due to the preparation processes of the February 27, 2010, giant earthquake that occurred in Chile. 
In the previous paragraphs, we investigated the form of the RBEP bursts observed before earthquakes in eastern Asia (Japan) and south-eastern America (Chile). In both of these cases, a pair of anomalous EBs were observed during each DEMETER semi-orbit, one near the earthquake epicenter, and the conjugate one in the other hemisphere (north or south). In the next paragraphs, we examine the flux-time profiles in another major seismogenic region of the globe: south-eastern Europe.

We investigated the electron observations during the most important earthquakes that occurred in the Greek territory during the life of DEMETER (2004-2010): (a) June 8, 2008, $\mathrm{M}=6.5$, Andravida, $37.93^{\circ} \mathrm{N} / 21.41^{\circ} \mathrm{E}$; (b) February 4, 2008, $\mathrm{M}=6.7$, Methoni, $36.22^{\circ} / 21.80^{\circ} \mathrm{E}$; and (c) January 8 , $2008, \mathrm{M}=6.8$, Kythira, $36^{\circ} \mathrm{N} / 23^{\circ} \mathrm{E}$. From this investigation, we selected and present in Figure 3 a representative example of the flux-time profile of the RBEP events observed by DEMETER above Greece throughout several days before each earthquake.

In Figure 3, after the high fluxes in the first part of upward semi-orbit 20955_1 (Figure 3a, b), which were observed in a region influenced by the South Atlantic Anomaly (SAA), DEMETER passed near the epicenter of the earthquake that occurred in Andravida on June 8, $2008\left(37.93^{\circ} \mathrm{N} / 21.41^{\circ} \mathrm{E}\right)$ and recorded a low flux background $\left(\mathrm{j}_{\mathrm{G}} \approx 2 \mathrm{e} / \mathrm{cm}^{2} \mathrm{~s} \mathrm{sr} \mathrm{keV}\right)$. This low electron flux background is representative of the fluxes observed by DEMETER in the Greek territory, in contrast to the normal high flux background observed above Japan as, for instance, in the case of the Japan-earthquake-induced EB shown in Figure $1\left(\mathrm{jJ} \approx 500 \mathrm{e} / \mathrm{cm}^{2} \mathrm{~s} \mathrm{sr} \mathrm{keV}\right)$.

The observations were made on June 5, 2008, about three days before the occurrence of the earthquake.
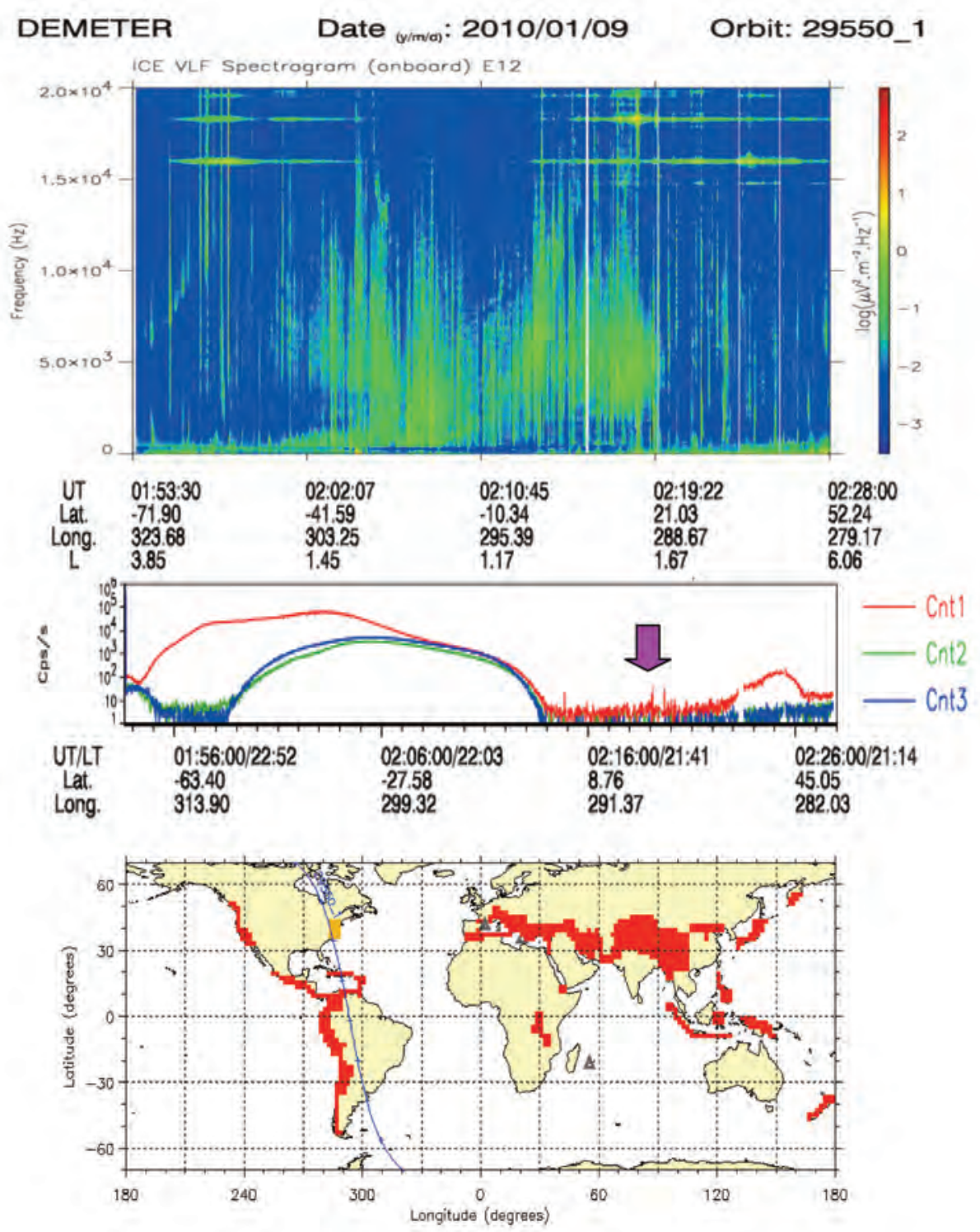

Figure 4. Observations from the DEMETER saellite on January 12, 2010, about 3 days before the Haiti earthquake occurred at 21:53 on January 12, 2010 $\left(18.46^{\circ} \mathrm{N} / 287.47^{\circ} \mathrm{E}\right)$. A pair of short-lived peaks were observed that were separated by a time interval of $\sim 1 \mathrm{~min}$, and were accompanied VLF $(\sim 2-10$ $\mathrm{kHz}$ ) wave activity. 


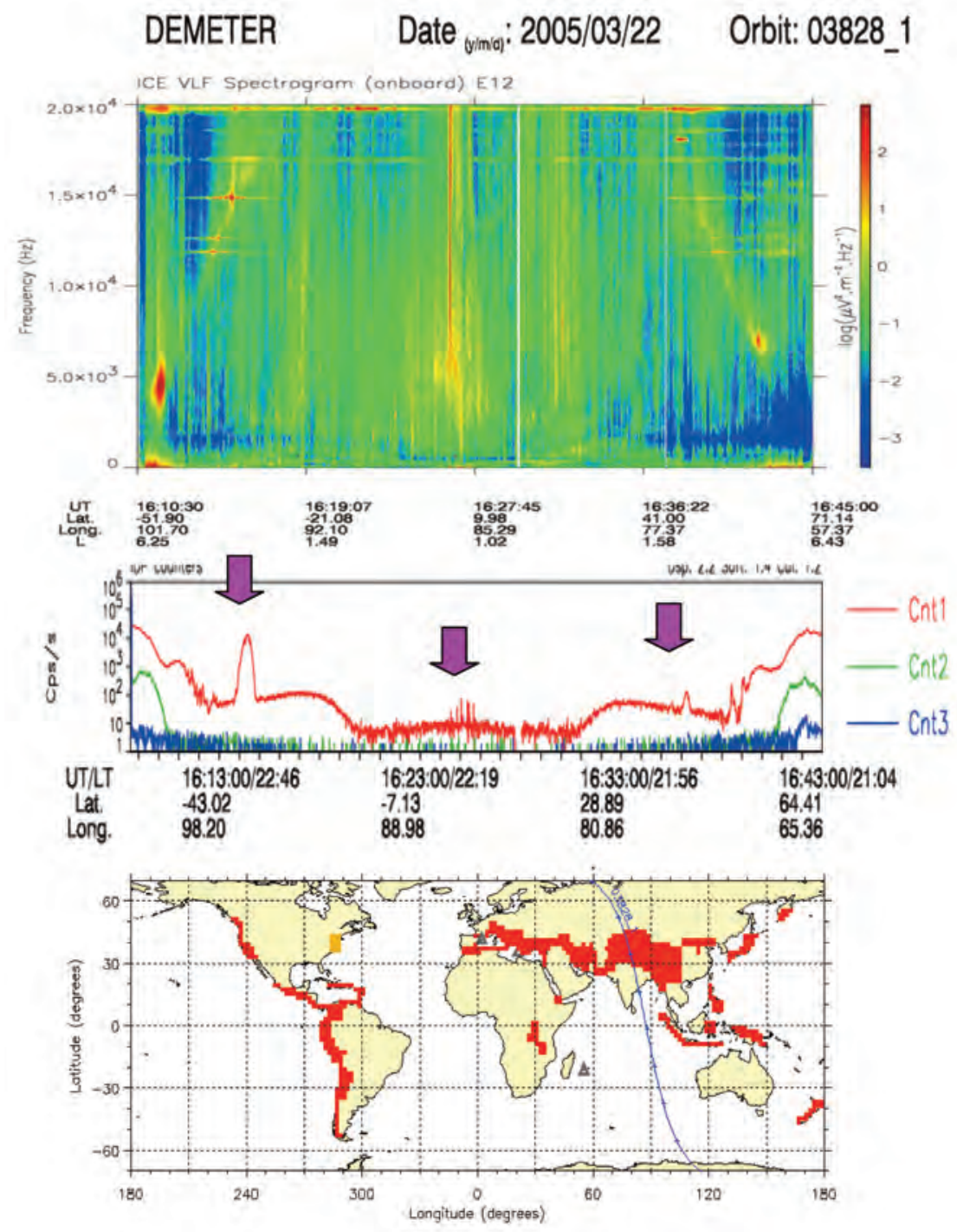

Figure 5. Observations from the DEMETER satellite related to the well-known giant $(\mathrm{M}=8.8)$ earthquake that occurred in Sumatra $\left(2.09^{\circ} \mathrm{N}, 97.11^{\circ} \mathrm{E}\right)$ on March 28, 2005. The observations reveal a flux-time profile with a sequence of short-lived intensity peaks observed above the region of the epicenter and accompanied by VLF wave activity in the range $\sim 3 \mathrm{kHz}$ to $>20 \mathrm{kHz}$, as well as a pair of EBs, with one in the north and the other symmetric one in the south.

Although the earthquake in Andravida occurred at a geographic latitude $\left(37.93^{\circ} \mathrm{N}\right)$ similar to that of the August 16,2005 , earthquake in Japan $\left(38.3^{\circ} \mathrm{N}\right)$, an anomalous electron activity 'above' Andravida was observed that was very different to that above Japan. Here, beside the much lower intensity background (with a flux ratio as low as $2 / 500$ ), instead of one peak superimposed on the (high) flux background, a sequence of ( $\sim 5-6)$ electron peaks are evident, which lasted for a total of $\sim 2 \mathrm{~min}$, with a peak-tobackground flux increase $\mathrm{p} / \mathrm{b}$ ranging between $\sim 10$ and $\sim 20$. Furthermore, the near Andravida EB is well related in time with the presence of a broadband ( 2-19 kHz) VLF activity (Figure 3a). A conjugate burst in a south region cannot be identified in this case, obviously due to the very high flux background (in particular at low energies; band 1).

A similar electron flux-time profile to that of the Andravida 2008 earthquake was observed on January 12,
2010, about 3 days before the Haiti earthquake that occurred at $21: 53$ on January $12,2010\left(18.46^{\circ} \mathrm{N} / 287.47^{\circ} \mathrm{E}\right)$, and which is presented in Figure 4. In this case, when the earthquake occurred at low latitudes, a pair of short-lived peaks were observed that were separated by a time interval of $\sim 1 \mathrm{~min}$, while the electric field spectrum extended in a moderately broad band of frequencies $(\sim 2-10 \mathrm{kHz})$, compared to the more broad spectra seen in Figures 1 (Japan) and 2 (Chile). The RBEP event observed above Chile concerns a unique time interval and a corresponding ionospheric region without a record of a conjugate EB.

Finally, Figure 5 shows the data relative to another well-known giant earthquake $(\mathrm{M}=8.8)$ that occurred in Sumatra $\left(2.09^{\circ} \mathrm{N}, 97.11^{\circ} \mathrm{E}\right)$ on March 28,2005 . For this earthquake, several studies reported variations in electromagnetic field and plasma parameters in the ionosphere [Liu et al. 2011]. Electron precipitation events 
were also observed in the ionosphere by DEMETER, well before (at least 2 weeks) the occurrence of the earthquake (data not shown). The case of the 2005 Sumatra earthquake is important from the point of view of the flux-time profile form, because the observations in this case reveal a new type compared to the flux-time profiles seen in the previous cases (Figures 1-4). A sequence of short-lived-intensity peaks was observed above the region of the epicenter ( 16:26:30-16:27:45 UT), which was accompanied by VLF wave activity in the range of $\sim 3 \mathrm{kHz}$ to $>20 \mathrm{kHz}$, as well as a pair of EBs, with one burst in the north (16:16-16:17 UT) and another symmetric to the previous one in the south (centered at $\sim 16: 38 \mathrm{UT}$ ).

3.2 Statistical results on the temporal evolution of radiation belt electron precipitation events before the earthquakes in Japan spatial redistribution

One of the most important results of the present study is the characteristic pattern of the temporal variations of the RBEP events we found before the occurrence of earthquakes in Japan. To check this pattern, we performed a statistical analysis and the results are presented next in this section. Figure 6 (bottom panel) shows the daily number $\mathrm{N}_{D G}$ of the low energy band 1 EBs observed by DEMETER for the time interval of August 2-20, 2005 in the longitude range $107^{\circ}$ $177^{\circ}$; i.e. $35^{\circ}$ eastwards and westwards of the earthquake epicenter $\left(142^{\circ} \mathrm{E}\right)$. A peak in the $\mathrm{N}_{D G} 8$ days before the earthquake is evident. About 15 days before the earthquake occurrence, the $\mathrm{N}_{D}$ started to increase, and it showed a minimum on the day of the earthquake, August 16 (Figure 6, short red bar). Figure 6 (top panel) shows the daily number $\mathrm{N}_{D L}$ of EBs observed by DEMETER all over the globe for the same time interval as for Figure 6 (bottom panel) (August 2$20,2008)$. We see that the distribution pattern of $N_{D G}$ all over the globe is similar to that observed in the area above the earthquake epicenter.

At this point, we examined whether the two curves were identical or not. We computed the relative frequencies $F_{D G}$ and $\mathrm{F}_{D L}$ over the total number of EBs of each distribution, and we use chi-squared $\left(\mathrm{X}^{2}\right)$ tests for the goodness of fit. We set the null hypothesis that: the distributions of the daily frequency FDG of EBs observed by DEMETER all over the globe (Figure 6 - bottom panel) and the daily frequency FDL of EBs observed by DEMETER locally in the longitude range $107^{\circ}$. $177^{\circ}$ (Figure 6 - bottom pane) in the time interval of August 2-20, 2005, are the same. For this reason, we determined the critical value of the $X^{2}$ distribution with degrees of freedom $\mathrm{df}$ $=18$ (number of days between August 2-20 $=19 ; \mathrm{df}=19-1=$ 18) from the suitable tables, and it was 37.156 at $\alpha=0.005$ [Mann 1998]. We computed the test value from 19 pairs of $F_{D G}$ and $\mathrm{F}_{D L}$ values $\mathrm{X}^{2}=7.75$. Since $7.75<31.5$, the decision is not to reject the null hypothesis. This result suggests that the temporal variation of the daily frequencies of the $\mathrm{EBs}_{\mathrm{DG}}$ and $\mathrm{F}_{D L}$ are identical at a $2.5 \%$ significance level. In addition, we evaluated the cross-correlation coefficient for the two curves, and there was a positive correlation between the distributions of the daily numbers of EBs $\mathrm{N}_{D G}$ and $\mathrm{N}_{D L}$. The crosscorrelation coefficient was evaluated to be as high as $\mathrm{r}=0.87$

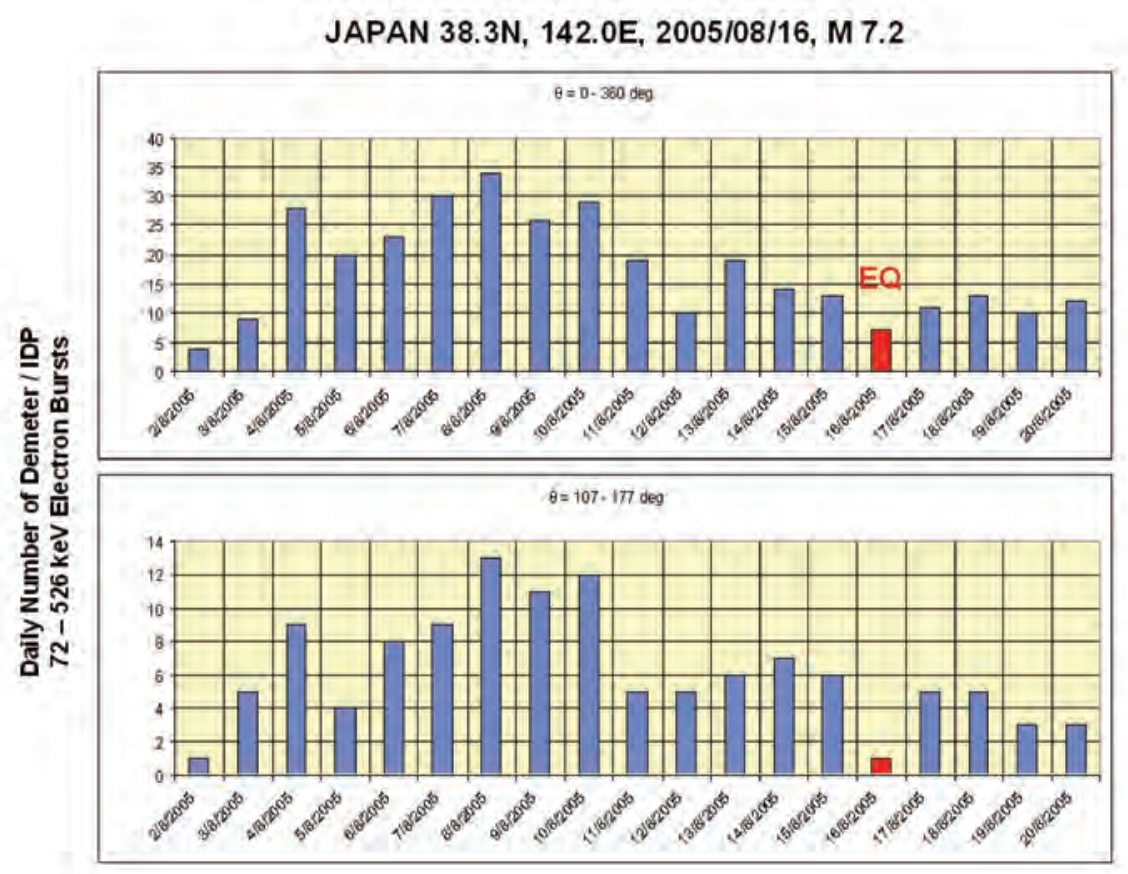

Figure 6. Temporal distribution of the daily number of EBs across the globe (top) and in a region extending $\pm 35^{\circ}$ eastwards and westwards of the epicenter longitude for the period August 2-20, 2005 including the day of a strong earthquake in Japan that occurred on August 16, 2005 (bottom). The correlation of the distributions is highly significant. 
for $\Delta \mathrm{T}=0$ (where $\Delta \mathrm{T}$ counts the number of days between the corresponding daily values $\mathrm{N}_{D G}$ and $\mathrm{N}_{D L}$ ).

We understand that the similarity of the two distributions of the DEMETER EB daily distribution suggests a strong dependence of the RBEP flux all over the globe on the precipitation caused by the 'local' electromagnetic processes of the earthquake preparation region; the opposite interpretation, i.e. a dependence of the local EB temporal evolution (Figure 6 - top pane) on a global phenomenon, is in contradiction to the fact that the boundary condition at the time of the minimum (August 16, 2008) is defined by the day of the earthquake occurrence. Therefore, almost certainly we can infer that the local electromagnetic processes of the earthquake preparation region influenced the RBEP all over the globe before the August 16, 2005, earthquake.

An extended (40 day) investigation of a large number of strong earthquakes in Japan led us to the conclusion that the temporal evolution of energetic precipitation in the upper ionosphere follows the pattern of the August 16, 2005, earthquake discussed above. This pattern is clearer when a strong future earthquake is separated by long times (at least 1 day) and/or takes place at distant places. Our statistical analysis was performed for $\mathrm{M}>6.7$ earthquakes in Japan in a geographic window with longitudes between $135^{\circ}-155^{\circ} \mathrm{E}$ and latitudes $36^{\circ}-47^{\circ} \mathrm{N}$ for the time interval from August 2004 to June 2008. There were 9 earthquake under these restrictions. From these 9 earthquakes, we selected these 9 earthquakes (numbered 1-9) for which complete DEMETER datasets were available, and Table 1 shows the appropriate information for these earthquakes. The first 6 columns of Table 1 after the numbering of the earthquakes in the first column show the time, the epicenter coordinates (longitude, latitude), the magnitude, the depth of the earthquakes, and the ratio of the daily number of EBs on the day of their maxima, as compared with their previous minimum values and the minimum values \pm 1 the earthquake days (see below). We see that earthquake \#3 $\left(46.6^{\circ} \mathrm{N}, 153.3^{\circ} \mathrm{E}\right)$ was the greatest earthquake that occurred in the greater Japan area during the time period examined in this statistical study, and after $\sim 35 \mathrm{~min}$ it was followed by earthquake $\# 4$, at almost the same location $\left(46.6^{\circ} \mathrm{N}\right.$, $\left.154.7^{\circ} \mathrm{E}\right)$ and with exactly the same epicenter $(10 \mathrm{~km})$. In the same way, earthquakes \#7 and \#8 were closely related in space and time.

An evaluation of the daily number $\mathrm{N}_{D L}$ of the local $\left( \pm 35^{\circ}\right)$ EBs on the days before and after the seismic events $\# 2$, \#3-4, \#5, \#6, \#7-8, and \#9 gave the following results. Earthquake \#2: 2, 7, 6, [7], 4, 6, 7; earthquakes \#3-4: 5, 7, 10, 12, [6], 3, 11, 10; earthquake \#5: 5, 11, 11, 7, [6], 9; earthquake \#6: 3, 8, 11, 8, 7, 11, 4, [7], 7; earthquakes \#7-8: 3, 7, 9, 11, [8], $5,3,3,10,10$; and earthquake \#9: $8,13,8,9,6,5,[8], 8$. The brackets here indicate the daily number $N_{D l}$ of the EBs on the day of the earthquake occurrence. A careful study of the daily variations suggests that before the earthquakes under examination, $\mathrm{N}_{D L}$ starts from low values, and then it always shows a local maximum before the day of the earthquake considered. The ratio of the maximum $\mathrm{N}_{D}$ over its initial value is $7 / 2,12 / 5,11 / 5,11 / 3,11 / 3$ and $13 / 8$, while the ratio of the maximum $N_{D L}$ over its value on the day of the earthquake \pm 1 day is $7 / 3,12 / 3,11 / 6,11 / 4,11 / 5,13 / 5$; these data are shown in the last columns of Table 1 , and they suggest that in all six of the cases, the form of the temporal distribution of the daily number of EBs follows the pattern of the distribution of the August 16, 2005, earthquake shown in Figure 6, in the sense that strong RBEP activity precedes each earthquake, which starts 3-6 days before the main shock. A careful examination in the whole set of data suggests that the long duration (13 days) of the intense RBEP seen in Figure 6 is instead due to 5 earthquakes with magnitudes $M>6$ that occurred between August 3 and 11; for this reason a 3-day RBEP period is also marked in the appropriate site of Table 1 . In a series of studies under preparation, we will present additional higher timeresolution indices, which we believe will better explain the pattern of the temporal evolution of the RBEP phenomenon.

\begin{tabular}{|c|c|c|c|c|c|c|c|c|c|}
\hline No & Date & $\begin{array}{l}\text { Time } \\
\text { (UTC) }\end{array}$ & $\begin{array}{l}\text { Lat. } \\
\left({ }^{\circ} \mathrm{N}\right)\end{array}$ & $\begin{array}{l}\text { Long. } \\
\left({ }^{\circ} \mathrm{E}\right)\end{array}$ & Magn. & $\begin{array}{l}\text { Depth } \\
(\mathrm{km})\end{array}$ & $\begin{array}{c}\text { Duration } \\
\text { (days) }\end{array}$ & $\begin{array}{c}\mathrm{EB}_{\mathrm{M}} / \mathrm{EB}_{\mathrm{S}} \\
\pm 35^{\circ}\end{array}$ & $\begin{array}{c}\mathrm{EB}_{\mathrm{M}} / \mathrm{EB}_{\mathrm{EQ}} \\
\pm 35^{\circ}\end{array}$ \\
\hline 1 & $2005 / 08 / 16$ & $02: 46: 28$ & 38.3 & 142.04 & 7.2 & 36 & $13(3)$ & $13 / 1(7 / 5)$ & $13 / 1(7 / 1)$ \\
\hline 2 & $2005 / 11 / 14$ & $21: 38: 51$ & 38.1 & 144.9 & 7.0 & 11 & 2 & $7 / 2$ & $7 / 3$ \\
\hline 3 & $2006 / 11 / 15$ & $11: 14: 13$ & 46.4 & 153.3 & 8.3 & 10 & 3 & $12 / 5$ & $12 / 3$ \\
\hline 4 & $2006 / 11 / 15$ & $11: 40: 55$ & 46.5 & 154.7 & 6.7 & 10 & 3 & & \\
\hline 5 & $2007 / 01 / 13$ & $04: 23: 21$ & 46.2 & 154.5 & 8.1 & 10 & 3 & $11 / 5$ & $11 / 6$ \\
\hline 6 & $2007 / 03 / 25$ & $00: 41: 57$ & 37.3 & 136.6 & 6.7 & 8 & 6 & $11 / 3$ & $11 / 4$ \\
\hline 7 & $2007 / 07 / 16$ & 01:13:22 & 37.5 & 138.4 & 6.6 & 12 & 3 & $11 / 3$ & $11 / 5$ \\
\hline 8 & $2007 / 07 / 16$ & $14: 17: 37$ & 36.8 & 134.9 & 6.8 & 350 & $3(+)$ & $11 / 3$ & $11 / 5$ \\
\hline 9 & $2008 / 05 / 07$ & $16: 45: 18$ & 36.2 & 141.5 & 6.9 & 27 & 5 & $13 / 8$ & $13 / 5$ \\
\hline
\end{tabular}

Table 1. Characteristics of the earthquakes with $M>6.7$ in the greater region of Japan. 


\begin{tabular}{|c|c|c|c|c|c|c|c|c|}
\hline Date & $\begin{array}{l}\text { Time } \\
\text { (UTC) }\end{array}$ & $\begin{array}{l}\text { Lat. } \\
\left({ }^{\circ} \mathrm{N}\right)\end{array}$ & $\begin{array}{c}\text { Long. } \\
\left({ }^{\circ} \mathrm{E}\right)\end{array}$ & Magn. & $\begin{array}{l}\text { Depth } \\
(\mathrm{km})\end{array}$ & $\begin{array}{c}\text { Duration } \\
\text { (days) }\end{array}$ & $\begin{array}{c}\mathrm{EB}_{\mathrm{M}} / \mathrm{EB}_{\mathrm{S}} \\
\text { all lat }\end{array}$ & $\begin{array}{c}\mathrm{EB}_{\mathrm{M}} / \mathrm{EB}_{\mathrm{EQ}} \\
\quad \text { all lat }\end{array}$ \\
\hline $2005 / 03 / 28$ & $16: 09: 36$ & 2.1 & 97.1 & 8.6 & 30 & 4 & $30 / 4$ & $30 / 16$ \\
\hline
\end{tabular}

Table 2. Characteristics of the catastrophic earthquake of March 28, 2005, in North Sumatra. The electron bursts in the two last columns are considered for DEMETER orbits at all latitudes.

Although the statistical results for the temporal evolution of the daily number of RBEP EBs are presented in Table 1 for Japan, we should point out that a similar pattern like that of Figure 6 has been confirmed for many earthquakes all over the globe. Such statistical results for Indonesia, western America and other seismogenic regions, as well as the statistical results for the whole globe at low and middle latitudes, is the subject of a manuscript under preparation. Here, we show some statistical results for one of the greatest and most catastrophic earthquakes of recent years at low latitudes, the earthquake of $\mathrm{M}=8.6$ in North Sumatra, on March 28, 2005. As we mentioned above when describing Figure 5, this earthquake was presented as an example of a special type of RBEP process. In this case, the electron precipitation was not a latitudinal confined event. On the contrary, the RBEP activity was observed as follows: (a) a series of spikes above the region of the epicenter; (b) one strong EB at the north latitudes; and (c) another EB symmetric to the previous one at south latitudes. For this earthquake, we show in Table 2 the data as for the earthquakes in Japan in Table 1, but including orbits all over the globe. The evaluation of the daily number $N_{D G}$ on the days before and after the March 28, 2005, earthquake gave the following results: $4,16,24,30,16$, [33], 31. The ratio of the maximum $\mathrm{N}_{D}$ over its initial value is $30 / 4$, while the ratio of the maximum $\mathrm{N}_{D L}$ over its value on the day of the earthquake \pm 1 day is $30 / 16$ (Table 2). These data are similar to those of Table 1, and they suggest that a strong increase in the number of RBEP EBs started 4 days before the earthquake occurrence. An examination of more data from DEMETER (data not shown) suggests that RBEPs accompanied by VLF and ULF activity were observable from at least March 12, 2005.

Figure 7 shows the distribution of the EBs recorded by DEMETER as a function of longitude for selected days before the Japan August 16, 2005, earthquake. In Figure 7, the longitude of the earthquake epicenter has been defined as a longitude with a value $\theta=0^{\circ}$. Distributions are presented for 5 days (Figure 7, top to bottom): (a) A day before the beginning of the EB daily rate $\mathrm{n}_{D}$ increasedecrease phenomenon (August 2, 2005); (b) The day of the maximum $E B$ daily rate $\mathrm{n}_{D}$ (August 8, 2005); (c) A day during the decreasing rate $\mathrm{n}_{D}$ (August 12, 2005); (d) The day of the earthquake occurrence (August 16, 2005); and (e) The day after the earthquake occurrence (August 17, 2005).

It is obvious that the daily number of EBs of Figure 7 varies according to the shape of the temporal evolution

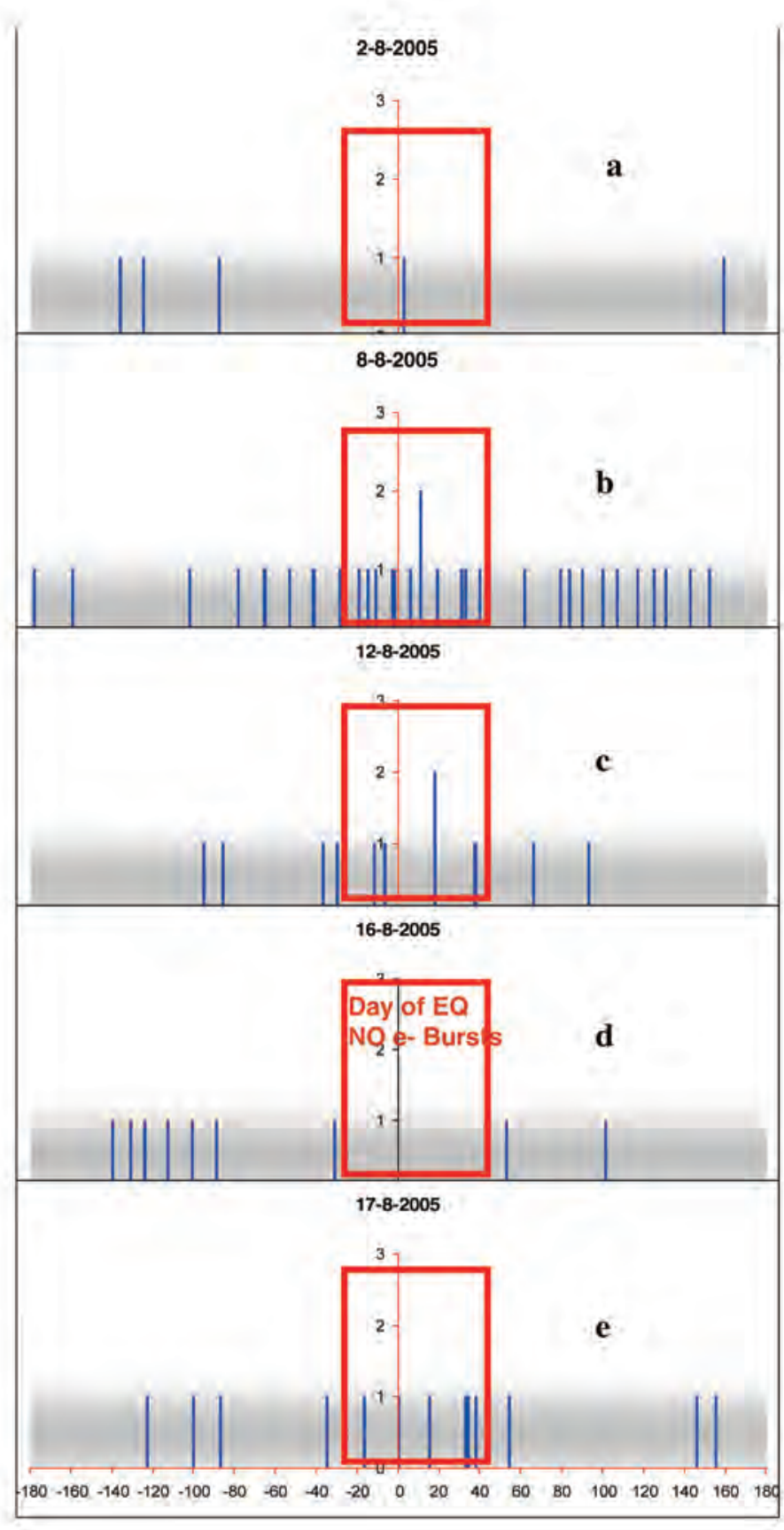

Figure 7. Distribution of electron bursts recorded by DEMETER as a function of longitude for selected days before the Japan August 16, 2005, earthquake. Longitude with a value $\theta=0^{\circ}$ has been defined as the longitude of the of the earthquake epicenter. Characteristics of the temporal evolution and the spatial distributions of the bursts are discussed in the text.

shown in Figure 6. Moreover, Figure 7 reveals two important new features concerning both the time evolution and the spatial distribution of the RBEP events. To make these 
features clearer, we draw a rectangle in each panel covering, in longitude, a region from $25^{\circ}$ westward to $45^{\circ}$ eastward of the epicenter location $\left(\theta=0^{\circ}\right)$. We will call this region around the earthquake the 'ER'. We see that:

(i) First, on the day of the earthquake, the IDP experiment onboard DEMETER revealed a quiet time period for electron precipitation in the ER above the earthquake epicenter. This RBEP 'silence' above the epicenter on the day of the earthquake occurrence recalls the statistical results of Nemec et al. [2009], who saw a decrease in the VLF wave intensity from $0 \mathrm{~h}$ to $4 \mathrm{~h}$ before the time of the main earthquake.

(ii) Secondly, the longitude extent of the EB distribution was reduced dramatically from August 8 to August 12 in the ER (around the region of the epicenter), with the distribution showing no EB within the ER on August 16 (as we mentioned above, from the point of view of the temporal evolution of $\mathrm{N}_{D L}$ ); we note that the EBs that correspond to the bars to the right of the ER in Figure 7, on August 12 and 16 , were most probably related to a ground-based transmitter in Europe, so the seismic-induced RBEP events reduction in the ER region actually had a very clear effect before the August 16 earthquake. The reduction in the RBEP events over the epicenter a few days before the occurrence of the earthquake resembles the concentration of the foreshocks before the occurrence of the main shock found in the case of the L'Aquila (Italy) earthquake of April 6, 2009 [Papadopoulos et al. 2010].

Here, we note that the minimum in the number of EBs does not always coincide with the date of earthquakes considered in the statistical sample of Table 1 and discussed above. This is sometimes due to the averaging of the numbers of EBs within a day (0-24 h/ UT) independent of the time of earthquake occurrence. For instance, earthquake \#6 of Table 1 shows a minimum 'before' the day of the earthquake occurrence, March 25, 2007, but the earthquake occurred at the beginning of this day, at $\sim 00: 42$; therefore, the number of EBs has actually shown a minimum closely related to the main earthquake shock. Furthermore, the date of earthquake \#9 in Japan (May 7, 2008) shows an increase in the daily number of $E B s N_{D L}$, this daily increase in the number of EBs is evidently affected by the preparation of the seismic region in China, which caused the catastrophic earthquake of May 12, 2008; however, fine time resolution data (data not shown) have demonstrated that before the earthquake occurrence in Japan, a $\sim 3$-h silence in the RBEP was observed in the top side ionosphere above the earthquake epicenter.

\section{Summary of observations, and discussion}

4.1 Dependence of electron precipitation events on the geographic coordinates.

In this study, we have extended our understanding of the earthquake-induced electron precipitation process. We find that earthquake-induced EBs show different forms that are dependent on the geographic location of the earthquake epicenter.

We investigated the earthquake-induced EBs at middle latitudes at depth, and in particular the earthquake-induced electron precipitation events above a broad area around Japan, and in the south-eastern Mediterranean (Greece), which were observed at similar (middle) latitudes. For the EB types at middle latitudes, we found systematic

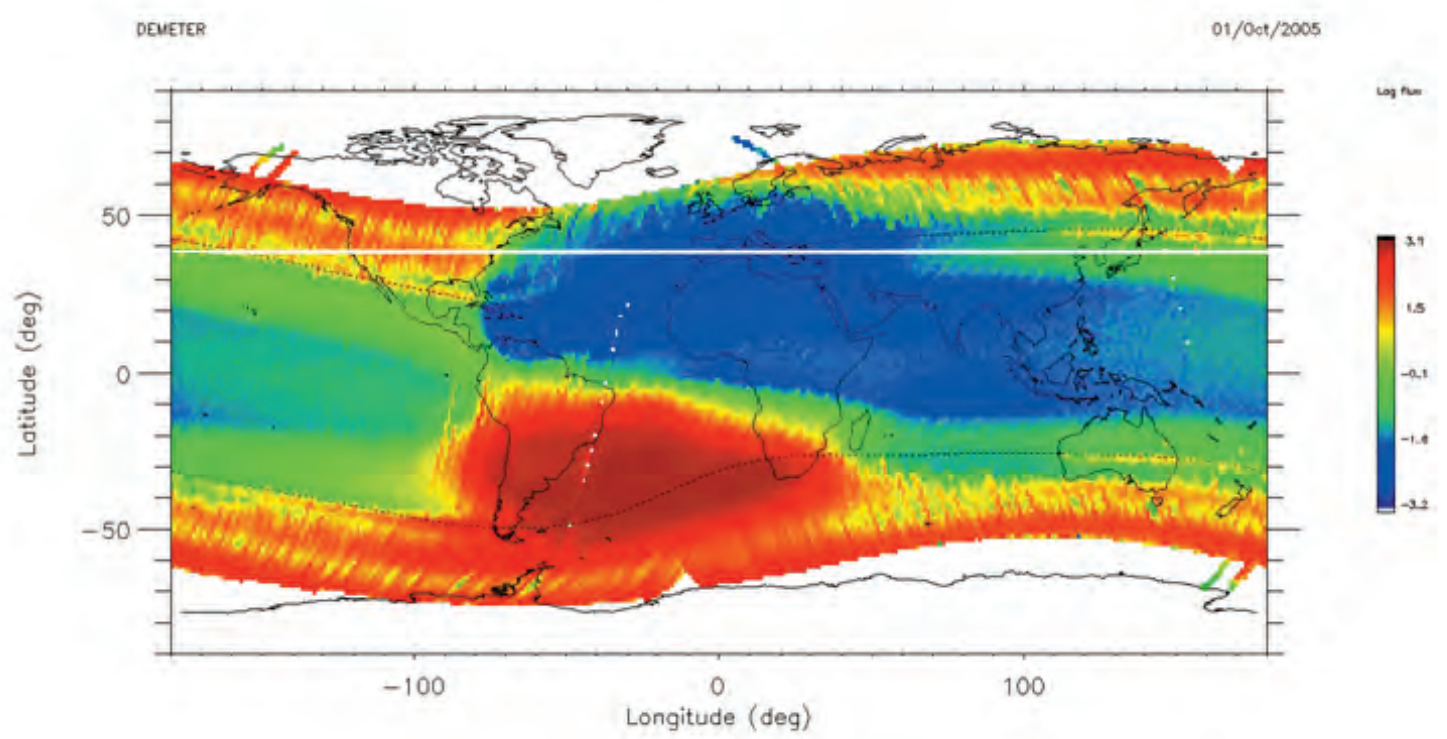

Figure 8. The average intensities of IDP/DEMETER 200 keV energy electrons for one year (October 2005 to October 2006). The electron distribution is highly affected by the SAA. 
differentiation in the observations above Japan and the Greece/south-eastern Mediterranean: although Greece is at approximately the same geographic latitude as Japan (white horizontal line at $\sim 39^{\circ} \mathrm{N}$ in the map of Figure 8, top panel), the electron precipitation events show very different forms in the flux-time profiles.

The main differences observed by DEMETER between the RBEP EBs before large earthquakes in Greece and Japan are the following: (1) The observed EBs over Japan are superimposed on a permanent high electron flux background $\mathrm{j}_{\mathrm{JP}}$, which is often called a 'pseudo-trapping region'. On the contrary, the electron flux background level in the top-side ionosphere of Greece jGR is much lower; the comparison of the corresponding measurements suggests a normal ratio $\mathrm{j}_{J P} /$ $\mathrm{j}_{J} \approx 10^{2}$. (2) The RBEP EBs observed before the earthquakes in Japan were usually associated with EBs in the south hemisphere. On the contrary, no conjugate EBs were found in the case of the earthquake precursory EBs observed above Greece. (3) The pre-seismic EBs over Japan most often showed a single flux enhancement that lasted for $\sim 2$ min to $3 \mathrm{~min}$ (with over $\sim 80 \%$ of the recorded EBs lasting for over $2 \mathrm{~min}$ in the statistical sample examined by Sidiropoulos et al.) [2011]. The pre-seismic electron precipitation activity over Greece lasted for almost the same time period, but the flux-time profile was composed of a sequence of several (3-8) short-lived intensity spikes. From the point of view of the RBEP, more work needs to be done in the future to study the possible differentiation between the energy spectra of the electron intensities in these two regions (Greece and Japan) as a function of latitude/L-shell parameters.

The evident reason for this systematic differentiation of the flux-time profiles between these two seismogenic regions that are situated at almost the same geographic latitude is evidently the different structures of the geomagnetic field. The SAA results in a north-south asymmetry of the average electron fluxes over a large range of longitudes, which includes South America, the Atlantic Ocean, Europe and Africa. This can easily be seen in Figure 8 , where the average intensity of the $\sim 200 \mathrm{keV}$ energy electrons for one year is displayed (October 2005 to October 2006). Therefore, we expect a differentiation of the detected earthquake-induced electron precipitation events over Greece and Japan, since Greece is affected by the SAA. In the case of earthquakes in Japan, the most frequent conjugate EBs are detected near to eastern Australia. A similar example to the appearance of a conjugate EB seen in the Japan earthquake (north hemisphere) was seen in the case of the south giant Chile earthquake also (conjugate burst in the north).

The details of the ways in which the earthquakeinduced electron precipitation events are formed in various geographic regions due to the differentiation of the Earth magnetic field over the globe are outside the scope of the present study. Here, we attempt only a classification of the various forms of the electron flux-time profiles on the basis of the large-scale variations in the geomagnetic field structure at various characteristic seismogenic regions all over the globe. More detailed theoretical interpretation will be the subject of a future manuscript.

As well as the earthquakes in Japan and Greece, we have presented preliminary results from a study of a few earthquakes that occurred at low latitudes (Haiti). The Haitirelated RBEP event reveals a third type of flux-time profile of the earthquake precursory EBs. We see that in this case, the satellite detected a unique event with a few short-lived intensity peaks in the absence of an observable ambient electron background, as in the case of the EBs observed above the south-eastern Mediterranean.

The fourth type of earthquake-induced electron precipitation event was revealed in the case of the Sumatra 2005 earthquake. In this case, the electron precipitation shows one peak near the epicenter, and simultaneously two other peaks, at north and south latitudes and almost symmetrical to the epicenter. This means that, in this last case, three distinct RBEP bursts occurred before a giant earthquake at low latitudes.

Further investigation is needed to achieve a more detailed description of the RBEP events based on additional observational characteristics: namely, the energy spectrum and the energy dispersion of the flux-time profiles. For instance, a preliminary investigation has suggested that earthquakes that occur at very high latitudes might show energy spectra that extend to higher energies $(>1 \mathrm{MeV})$ than those observed at middle latitudes. More deep understanding of the observed RBEP bursts will be possible after investigations into the physical mechanisms that are characteristic of these seismically induced VLF emissionparticle interactions that lead to precipitation, which is the subject of a following study.

In this report, we have continued to provide new material that supports our previous data that strong RBEPs precede strong earthquakes by a few days [Anagnostopoulos et al. 2010, Sidiropoulos et al. 2010]. Of note, we have not provided results from a large statistical sample of earthquakes that covers the whole globe. It is our research strategy here to first elaborate upon the characteristic features of the major seismogenic regions around the globe. The possible reasons for the observed differences of longitudinal and latitudinal distributions of EBs for different seismogenic regions of the globe might be based in magnetic declination (large declination, as is characteristic of American sectors, creates the problem of conjugation effects between hemispheres), and also in different L-parameters for different longitudes (this factor determines whether the magnetic flux tube of the seismogenic region is inside or outside the radiation belt). These problems will also be considered in our following studies. 
In this way, we have accumulated with time more information about spatial differentiation of RBEP signals. As a result, we improve our knowledge for the selection criteria of EBs for the performing of an automatic procedure on a very broad statistical sample in the future.

\subsection{Temporal evolution of electron precipitation before large} earthquakes

Furthermore, our studies have demonstrated that there is a permanent characteristic temporal variation in the behaviors of the flow of inner Van Allen radiation belt electrons in the upper ionosphere that lasts for several days to a few weeks before strong earthquakes in Japan.

This phenomenon resembles a 'rain' of electrons from the Van Allen belts, which begins with an incremental rate several days to a few weeks before major earthquakes. These then show a maximum, and finally this rain becomes weaker, with a minimum or a pause in the electron precipitation some hours before the onset of an earthquake. The effect is observed locally, over the earthquake preparation zone, although in cases of strong earthquakes, the precipitating electrons can control the behavior of the drifting electrons over a wide ranges of longitudes.

We find that this kind of temporal evolution in the space measurements of energetic electrons has been known for several electromagnetic geophysical, ionospheric and space physics parameters before those of strong earthquakes (Pulinets and Boyarchuk 2004). For instance, we recall the characteristic temporal patterns of the ULF magnetic field activity detected by ground magnetometers some weeks before an earthquake [Hayakawa et al. 1996a, b]. In this case, the ULF polarization ratio $\mathrm{Z} / \mathrm{H}$ of the magnetic field starts increasing gradually, reaches a maximum value, and then around the time of the earthquake it shows a deep minimum. It has been surmised by Hayakawa et al. [1996a] that these ULF emissions are related to earthquake preparation processes.

It is possible that the magnetic field ULF polarization ratio $\mathrm{Z} / \mathrm{H}$ changes before strong earthquakes and is related to a redistribution of the Sq electric current system in the ionosphere [Duma and Ruzhin 2003]. It is also possible that the ground ULF polarization and the radiation belt electron temporal evolution are related to the Sq ionospheric current variations under a series of physical processes that are observed as almost simultaneous changes in ground, ionospheric and radiation belt physical parameters.

We found that the temporal pattern of RBEP changes, with a maximum flux several days before and a minimum flux around the earthquake occurrence time, is clear in 7 of the $7 \mathrm{M}>6.7$ earthquakes that occurred in or near Japan between August 2004 and June 2008 (we actually found 9 earthquakes with $M>6.7$, but in 2 cases two $M>6.7$ earthquakes occurred within about half a day and in the present study are related to the same general precursor signal; more detailed analysis that can separate the signals of these earthquakes will be presented in a future study). Our investigation suggests that this pattern of temporal evolution is clear when we study the occurrence of a single earthquake, i.e. when no other strong earthquakes occur in close areas and/or times. Furthermore, we found that for a great earthquake in Japan (August 16, 2005), this temporal evolution pattern is not only clear above the area of the earthquake epicenter, but it appears almost the same when the daily number $N_{D G}$ of the EBs over all of the globe are averaged (Figure 7). This finding suggests that most probably the earthquake preparation process is strong enough in its relation to the electromagnetic phenomena in the atmosphere-ionosphere-radiation belts that they can control the global energetic electron precipitation at low altitudes.

Furthermore, we have presented in this report a pair of intense RBEP bursts with one EB above the epicenter of the 2010 Chile earthquake, and its conjugate EB at north latitudes. These two intense bursts were detected by DEMETER (Figure 2) before the giant earthquake in Chile in the daytime upper ionosphere under very weak, moderately broad, VLF activity; because of the strong ionospheric absorption of the emitting radiation through the daytime ionosphere, no VLF electromagnetic emissions from the ground were recorded by the ICE instrumentation. This finding most probably suggests that the EBs of February 26, 2010, the day before the giant Chile earthquake, are almost certainly due to the preparation processes of the February 27, 2010, earthquake that occurred in Chile. Furthermore, it might suggest that the radiation belt electrons in this case do not interact with VLF radiation emitted from the ground (ground transmitter or seismic VLF radiation), but from an increased registration of VLF noise in the radiation belts that was caused by the influence of the anomalous electric field above the earthquake epicenter [Pulinets and Boyarchuk 2004]. In the case examined here, it appears that the electrons reach the dayside ionosphere of Chile after a strong interaction in the nightside radiation belts.

\section{Conclusions}

In this report, we provide significant new information on the phenomenology and some physical processes related to RBEP, starting several days before great earthquakes $(M>6.5)$. The main results of our study are the following: (1) Earthquake precursory RBEP events show flux-time profiles with: (a) two EBs at middle latitudes, with one burst above the future epicenter and a conjugate one in the other hemisphere (Japan, Chile); (b) only one EB at north middle latitudes, when the SAA affects the south hemisphere (south-eastern Europe/Greece); (c) one EB above an earthquake epicenter at low latitudes (Haiti); and (d) one EB above an earthquake epicenter at low latitudes and two symmetric EBs at north and south latitudes (Sumatra). (2) For earthquakes in Japan, a standard temporal variation of the number of EBs was found, 
which begins with an incremental rate several days before major earthquakes, and which after a maximum, decreases so that electron precipitation ceases above the region of the future epicenter a few hours before the occurrence of the earthquake. (3) The analysis of the spatial distribution of the EBs for the earthquake of August 16, 2005, in Japan reveals that the RBEP bursts were reduced in the space near the epicenter before the earthquake occurrence. (4) Strong RBEP bursts above the Chile earthquake were observed not only in the nightside, but also in the dayside upper ionosphere.

The present study was based on results from a systematic study of the DEMETER satellite measurements at low and middle latitudes before very strong earthquakes (i.e. $M>6.5$ ), but the results from an investigation not yet published suggest that such events are also observable before earthquakes with lower magnitudes $(M>\sim 5)$.

We understand the radiation belt energetic electron precipitation related with an earthquake as a ring in the chain of electromagnetic processes that can start above the Earth surface with the anomalous electric field, which can cause an increase in the VLF electric field wave activity in the magnetosphere. It has been suggested that a cyclotron resonance interaction between VLF waves and radiation belt energetic electrons is responsible for variations in the electron velocity phase space, and as a result, a part of the trapped electrons of the radiation belt change their pitch angles and travel towards the Earth, where they are recorded by low orbit satellites in the topside ionosphere. It is important to note that the ionization produced by the precipitation of electrons from the radiation belts in the lower ionosphere produces disturbance in the $\mathrm{D}$ region of the ionosphere at night, which is then observed both from ground and space instrumentation [Pulinets 2011].

The results of the present study might open a new window in earthquake prediction research. We note that the methodology of radiation belt energetic particle events earthquake precursor signals has the particular advantage of studying distant earthquake preparation regions, because of the fast eastward drifting of the energetic electrons.

Recent studies have started to use systematic analyses of several physical and environmental parameters, such as temperature and concentrations of electrons, VLF/ULF activities and RBEP in the ionosphere, thermal infrared radiation, radon/ion activities, and air temperature/ humidity in the atmosphere. These parameters have been found to be earthquake precursors. We believe that such approaches will achieve high confidence levels in earthquake prediction, at least in some cases, in future years.

Acknowledgements. The authors thank Drs. Sauvaud and Berthelier for providing the DEMETER data, and Dr I. Vesselovsky for useful discussions during the stay of the lead author in the Skobeltsyn Institute of Nuclear Physics, Moscow University, Russia.

\section{References}

Abel, B. and R.M. Thorne (1998). Electron scattering loss in Earth's inner magnetosphere 1. Dominant physical processes, J. Geophys. Res., 103, 2385-2396; doi: 10.1029/ 97JA02919.

Aleksandrin, S. Yu., A.M. Galper, L.A. Grishantzeva, S.V. Koldashov, L.V. Maslennikov, A.M. Murashov, P. Picozza, V. Sgrigna and S.A. Voronov (2003). High-energy charged particle bursts in near-Earth space as earthquake precursors, Ann. Geophys., 21, 597.

Anagnostopoulos, G. and V. Rigas (2009). Variations of energetic radiation belt electron precipitation observed by Demeter before strong earthquakes, EGU Abstracts.

Anagnostopoulos, G., V. Rigas, M. Athanasiou, A. Iliopoulos, E. Vassiliadis and N. Iossifidis (2010). Temporal Evolution of Energetic Electron Precipitation as a Promising Tool for Earthquake Prediction Research: Analysis of IDP/ DEMETER Observations, In: Proceedings of the 9th International Conference of the Hellenic Astronomical Society, proceedings of a conference held 20-24 September 2009 in Athens, Greece, edited by K. Tsinganos, D. Hatzidimitriou and T. Matsakos, Astronomical Society of the Pacific, San Francisco, 424, 67-74.

Anagnostopoulos, G. and A. Papandreou (2012). Space conditions during a month of a sequence of six $\mathrm{M}>6.8$ earthquakes ending with the tsunami of December 26, 2004, Nat. Hazards Earth Sys. Sci. (in press).

Boskova, J., J. Smilauer, P. Triska and K. Kudela (1994). Anomalous behaviour of plasma parameters as observed by the intercosmos 24 satellite prior to the Iranian earthquake of 20 June 1990, Studia Geophys. Geod., 38, 213.

Duma, G. and Y. Ruzhin (2003). Diurnal changes of earthquake activity and Geomagnetic Sq-variations, Nat. Hazards Earth Sys. Sci., 3, 171-177.

Eftaxias, K., V.E. Panin and Ye. Ye. Deryugin (2007). Evolution-EM signals before earthquakes in terms of mesomechanics and complexity, Tectonophysics, 431, 273-300.

Fidani, C., R. Battiston and W. Burger (2010). A study on the correlation between earthquakes and NOAA satellite energetic particle bursts, Remote Sens. Environ., 2 (9), 2170-2184; doi: 10.3390/rs2092170.

Galper, A.M., S.V. Koldashov and S.A. Voronov (1995). High energy particle flux variations as earthquake predictors, Adv. Space Res., 15, 131-134.

Ginzburg, E.A., A.B. Malishev, I.P. Proshkina and V.P. Pustovetov (1994). Correlation of strong earthquakes with radiation belt particle flux variations, Geomagn. Aeron., 34, 315-320 (English Translation).

Green, J.L. and S.F. Fung (2005). Distribution and origin of Plasmaspheric Plasma waves, In: Inner Magnetosphere interactions, edited by J. Burch, M. Schulz and $\mathrm{H}$. Spence, Geophys. Monogr. Ser., 159, 113-126.

Hattori, K. (2004). ULF Geomagnetic Changes Associated 
with Large Earthquakes, Terr. Atmos. Ocean. Sci., 15 (3), 329-360.

Hayakawa, M., R. Kowate, O. A. Molcanov and K. Yomoto (1996a). Results of ultra-low-frequency magnetic measurements during the Guan earthquake of 8 August 1993, Geophys. Res. Lett., 23 (3), 241-244.

Hayakawa, M., O.A. Molcanov, T. Ondoh and E. Kawai (1996b). The precursory signature effect of the Kobe on VLF subionospheric signals, J. Comm. Res. Lab., Tokyo, 43, 160 .

Inan, U.S., D. Piddyachiy, W.B. Peter, J.A. Sauvaud and M. Parrot (2007). DEMETER satellite observations of lightning-induced electron precipitation, Geophys. Res. Lett., 34, L07103; doi: 10.1029/2006GL029238.

Kopytsenko, Y., T.G. Matiashvili, P.M. Voronov, E.A. Kopytsenko and O.A. Molchanov (1990). Ultra low frequency emission associated with Spitak earthquake and following after shock activity using geomagnetic observatories Dusheti and Vrtya, IZMIRAN, 3(888).

Kuznetsov, S. and I. Myagova (2002). Quasi-trapped electron fluxes $(>0.5 \mathrm{MeV})$ under the radiation belts: analysis of their connection with geomagnetic indices, J. Atmos. Sol.-Terr. Phy., 64 (5-6), 601-605.

Liu, C.Y., J.Y. Liu, W.S. Chen, J.Z. Li, Y.Q. Xia and X.Y. Cui (2011). An integrated study of anomalies observed before four major earthquakes: 2004 Sumatra M9.3, 2006 Pingtung M7.0, 2007 Chuetsu Oki M6.8, and 2008 Wenchuan, M8.0, J. Asian Earth Sci., 41, 401-409.

Mann, S.P (1998). Introductory Statistics, John Wiley \& Sons.

Nemec, F., O. Santolik and M. Parrot (2009). Decrease of intensity of ELF/VLF waves observed in the upper ionosphere close to earthquakes: a statistical study, J. Geophys. Res., 114, A04303; doi: 10.1029/2008JA013972.

Ouzounov, D., K. Hattori and J.Y. Liu (2011). Validation of Earthquake Precursors - VESTO, J. Asian Earth Sci., 41, 4-5.

Papadopoulos, G., M. Charalampakis, A. Fokaefs and G. Minadakis (2010). Strong foreshock signal preceding the L' Aquila (Italy) earthquake(M 6.3) of 6 April 2009, Nat. Hazards Earth Sys. Sci., 10, 19-24.

Parrot, M. (Ed.) (2006). First results of the DEMETER micro-satellite, Planet. Space Sci., 54 (5), 411-558.

Paulikas, G. (1975). Precipitation of Particles at Lows and Middle Latitudes, Rev. Geophys., 13 (5), 709-734.

Pulinets, S.A. and A.D. Legen'ka (2003). Spatial-Temporal Characteristics of Large Scale Distributions of Electron Density Observed in the Ionospheric F-region before Strong Earthquakes, Cosmic Res., 41, 221-229.

Pulinets, S.A. and K. Boyarchuk (2004). Ionospheric Precursors of Earthquakes, Springer.

Pulinets, S.A. (2011). The synergy of earthquake precursors, Earthq. Sci., 24, 535-548; doi: 10.1007/s11589-0110815-1
Pulinets, S. and D. Ouzounov (2011). Lithosphere-Atmosphere-Ionosphere Coupling (LAIC) model - An unified concept for earthquake precursors validation, J. Asian Earth Sci., 41, 4-5.

Rozhnoi, A., M. Solovieva, O.A. Molcanov, P.-F. Biagi and M. Hayakawa (2007). Observation evidences of atmospheric Gravity Waves induced by seismic activity from analysis of subionopsheric LF signal spectra, Nat. Hazards Earth Sys. Sci., 7, 625.

Sauvaud, J.A., T. Morceau, R. Maggiolo, J.P. Treilhou, J. Jacquey, A. Cros, J. Coutelier, J. Reazaud, E. Penou and M. Gandloff (2006). High energy electron detection onboard DEMETER: the IDP spectrometer, description and first results on the inner radiation belt, Planet. Space Sci., 54 (5), 502-511.

Sauvaud, J.-A, R. Maggiolo, C. Jacquey, M. Parrot, J.-J. Berthelier, R.J. Gamble and C.J.A. Rodger (2008). Spectral domain form of new variational expression for very fast calculation of multilayered lossy planar line parameters, Geophys. Res. Lett., 35.

Sidiropoulos, N., G. Anagnostopoulos and V. Rigas (2011). Comparative study on earthquake and ground based transmitter induced radiation belt electron precipitation at middle latitudes, Nat. Hazards Earth Sys. Sci., 11, 1-13; doi: 10.5194/nhess-11-1-201.

Sgrigna, V., L. Carota, L. Conti, M. Corsi, A.M. Galper, S.V. Koldashov, A.M. Murashov, P. Picozza, R. Scrimaglio and L. Stagni (2005). Correlations between earthquakes and anomalous particle bursts from SAMPEX/PET satellite observations, J. Atmos. Sol.- Ter. Phy., 67, 1448.

Trakhtengerts, V.Y. and M.J. Rycroft (2008). Whistler and Alfvén Mode Cyclotron Masers in Space, Cambridge University Press, Cambridge, New York, Melbourne, Madrid, Cape Town, Singapore, Saõ Paulo, Delhi, 368 pp.

Vampola, A. (1983). Observations of VLF Transitter-Induced Depletions of inner zone electrons, Geophys. Res. Lett., 10 (8), 619-622.

Varotsos P., N. Sarlis, M. Lazaridou and P. Kapiris (1998). Transmission of stressed induced electric signals in dielectric media, J. Appl. Phys., 83, 60-70.

Zhang, Z., X. Li, X. Shen, Y. Ma, H. Chen, X. You and Y. Yuan (2010). DEMETER satellite Observations of Particle Burst Prior to Chile Earthquake, http: / / arxiv.org/ PS_cache/arxiv/pdf/1011/1011.3592v1.pdf.

\footnotetext{
${ }^{\star}$ Corresponding author: Georgios Anagnostopoulos,

Department of Electrical and Computer Engineering, Demokritos University of Greece, Xanthi, Greece;

email: ganagno@ee.duth.gr.
}

C 2012 by the Istituto Nazionale di Geofisica e Vulcanologia. All rights reserved 